\title{
Intelligent Campus Service based on Mobile Internet
}

\author{
Jinping $\mathrm{Hu}$ \\ Jiangxi University of Engineering, Jiangxi, Xinyu,338000 \\ GJJ181144 Science and Technology Research Project of Jiangxi Education Department.
}

\author{
key words Mobile Internet; Intelligent Campus Service
}

\begin{abstract}
At present, with the development of society and times, the development of mobile Internet is becoming more and more rapid. at the same time, more and more people begin to pay attention to the development of mobile Internet, and mobile Internet has gradually become an irreplaceable existence in people's lives. In teaching, mobile Internet has also impacted on the traditional teaching mode. Both teachers and students begin to use mobile Internet for teaching and learning. This paper mainly focuses on the analysis and research of intelligent campus service based on mobile Internet.
\end{abstract}

\section{Introduction}

In the information age, the information construction of higher vocational colleges has slowly developed from the campus network to the intelligent campus. The construction of intelligent campus is tantamount to providing a good communication platform for teachers and students. Teachers and students can communicate through intelligent campus. At the same time, intelligent campus also integrates campus resources and realizes resource sharing. Because smart phones are constantly updated, teachers and students begin to expect that the intelligent campus network can also be used through mobile terminals, and access to information through mobile terminals can also be more convenient, no matter when and wherever, can communicate. So, using mobile interconnection, The construction of intelligent campus has become one of the hot topics in the campus at present, and this is also the inevitable trend of the development of information construction in higher vocational colleges at the later stage. Only the information construction in colleges and universities is constantly improving and making progress, can we meet the needs of teachers and students, so that students and teachers can receive their own needs and interested content.

Different data and information will show different characteristics in the network, what users will really be interested in is only a small part of tens of thousands of data, find the data and information that users need and are interested in, and provide these data and information to users, which is the main task of mobile Internet. In the traditional network, users often spend a lot of energy and time to filter the information until they find the information they need, which is because the traditional network can not accurately search and push, and even a lot of search results are unrelated to the user's search content, which greatly wastes the user's time, and in order to change it. Change the dilemma of the traditional network, the mobile Internet should be born. Mobile Internet is the product of big data era, so all data and information can be integrated and processed in big data era, and users can naturally get more accurate search results. At this stage, the focus of information construction has been on personalized services, information construction should be based on the preferences and needs of each user, accurate push to users, through the mobile Internet, to meet the needs of users. The emergence of intelligent campus provides a platform for teachers and students to meet the personalized needs of teachers and students, so that teachers and students All students have access to the information they need.

The research and development and application of different technology terminals and the continuous expansion of the scope of mobile Internet can effectively help students and teachers to obtain the required information through the mobile Internet. At present, teachers and students are used to browsing information on mobile phones, so teachers and students can use their fragmentation time to learn more information. In addition, different schools also begin to establish information sharing, intelligent campus can help teachers and students to obtain more information 
resources, and effectively reduce the retrieval time.

\section{2. the technology of intelligent campus platform construction and the technology of mobile terminal}

\begin{tabular}{|c|c|c|}
\hline \multicolumn{2}{|c|}{ Intelligent campus platform construction technology and mobile terminal technology. } \\
\hline The construction technology of intelligent campus platform & \multirow{2}{*}{ implementation technology of mobile terminal } \\
\hline $\begin{array}{c}\text { Analysis and Collection } \\
\text { of Information subject }\end{array}$ & Promotion of information & \\
\hline
\end{tabular}

\subsection{The construction technology of intelligent campus platform}

\subsubsection{Analysis and Collection of Information subject}

Generally speaking, a lot of information can be collected in the Internet, users can only enter keywords to find keywords related information, and if users search for keywords on the intelligent campus platform, there will be other situations, such as because the information in the Internet is constantly updated, so students can find the information they really need. Moreover, the main users of the intelligent campus service platform are students and teachers, that is to say, the Internet must provide teachers and students with the information they want to know.

\subsubsection{Promotion of information}

The mobile internet can push the information to the user, and the user can also know the progress of the information push by querying or texting, so long as the user is connected to the server, he can receive the push information. At the same time, both students and teachers can learn the information they need on the information platform, and the intelligent campus platform can also deliver more information to teachers and students through personalized service.

\section{2 implementation technology of mobile terminal}

At this stage, most of the smartphones on the market are Android, with the exception of the iPhone's own iOS, the most market share of the Android system. Therefore, the main client of the intelligent campus service platform based on the mobile network is also a mobile phone running the Android system, and an appropriate amount of other system information service is included therein.

\section{Application of Mobile Internet Technology in Intelligent Campus Service platform}

\subsection{The scheme of platform construction}

On the intelligent campus service platform, there are many different functions, and these functions also represent different services, these services are information information and campus services, information push and so on. The establishment of intelligent campus platform connects the network facilities of the school together and becomes a whole. When users want to use the mobile Internet for information browsing, users can connect with the server of the platform and transmit information. The intelligent campus platform includes two kinds of clients, which are divided into student-specific and teacher-specific. The student-specific client will provide the students with the services they need, while the teacher-specific client will provide the students with the services they need, while the teacher-specific client will provide the students with the services they need. Teachers will be provided with special services for teachers.

\section{2 platform information module and information promotion module}

Setting up a platform information module can help users quickly and conveniently understand the information of the relevant platform. At the same time, only users have mobile terminals, on the mobile terminal, they can provide users with the information columns that users need. At the same time, they can also manage user comments, continuously simplify the user's operation process, so that users can retrieve the content they need without much time and effort. At the same time, to update the information, the user only needs to drop down the page, which also facilitates the 
operation of the user. The personalized management module also helps users to realize the demand for information personalization, and sets up a platform information promotion model. Block can help students understand school-related activities and related curriculum arrangements, and students can also set up this, can choose to accept information or block information.

\section{Conclusion:}

Intelligent campus is based on the mobile Internet, so the intelligent campus information push way is more intelligent and personalized, students'information platform gradually from static to dynamic, the school's website is constantly improved, because of the division of different sections, so teachers and students can quickly view according to their own needs to know the information category and the information category they want to know, so, intelligent campus not only meet the needs of information diversity, but also enrich campus life.

\section{References:}

[1] Personalization -- The Development Trend of Information Service in Network Environment [J].

[2] Qiao Hongli. Science and Technology Information (Science Teaching and Research).2007(35). On Library Information Service Based on WeChat Platform [J]. Zhou Li. Lantai.2019(16).

[3]15th 2003-2017 China International Software and Information Services Fair [J]. Internet Weekly.2017(10).

[4] The personalized information service of the university library based on Web2.0[J]. Yin Zhiqing. Journal of Wuhan Institute of Marine Science and Technology. 2013 (03)

[5] discussion on the application of personalized information service in small and medium-sized enterprises [J]. Tang Xilin. Technology and innovation management. 2011 (03)

[6] Research on the practice of personalized information service in digital library[J]. Ji Xianwu, Chen Xiaodong, Jing Wanfu, and Sun Suping. Agricultural network information. 2011 (05)

[7] On individualized information service in electronic commerce [J]. Chen Lan, Dai Xiaoli. Information management in China. 2009 (18)

[8] on how libraries in the network age provide high quality information services [J]. Hou Hui. Health vocational education. 2009 (06) 